\title{
KAJIAN POTENSI BANDAR SENAPELAN SEBAGAI KAWASAN WISATA SEJARAH DAN BUDAYA DI PEKANBARU
}

(Tinjauandari Aset Peninggalan Arsitektur Rumah Tradisional Melayu)

\author{
Oleh : Titin Sundari, Rika Cheris, Repi Repi \\ titin@unilak.ac.id, rika.cherish@unilak.ac.id, repi@unilak.ac.id
}

Prodi Arsitektur Fakultas Teknik Universitas Lancang Kuning Pekanbaru

\begin{abstract}
Abstrak.
Bandar Senapelan sebagai daerah asal dari Kota Pekanbaru memiliki aset peninggalan arsitektur berupa rumah-rumah tradisional Melayu yang mempunyai ciri khas tertentu sebagai bukti sejarah yang nyata terhadap perkembangan kota Pekanbaru. Namun karena belum adanya program pemeliharaan kawasan ini secara komprehensif dan konkrit, maka dikhawatirkan keberadaannya akan punah dan masyarakat kota Pekanbaru tidak mempunyai bukti atau identitas lagi akan keberadaan kotanya. Aturan Pemerintah sebenarnya sudah ada namun perlu ditindak lanjuti oleh stakeholder kota. Nilai sejarah dan budaya yang terdapat di Bandar Senapelan akan mampu mengangkat jati diri daerah ini dan juga bisa menjadi kawasan pariwisata alternatif bagi masyarakat kota.

Penelitian ini bertujuan untuk melihat sejauh mana potensi yang dimiliki oleh Bandar Senapelan yang mempunyai aset peninggalan arsitektur rumah tradisional Melayu, agar di lestarikan dan dipelihara sehingga bisa dimanfaatkan menjadi sesuatu yang lebih menarik, sekaligus untuk menjadi aset wisata sejarah dan budaya Melayu di kota Pekanbaru.Mekanisme penelitian akan dilakukan dengan metode fishbone dan penelitian ini masih berada pada posisi dasar dari pada sebuah Road Map penelitian yang telah di rencanakan pada bagian berikutnya dalam proposal ini.

Hasil dari penelitian didapat bahwa potensi warisan berwujud (tangible) dibagi beberapa kelompok. Kelompok bangunan tradisional seperti rumah bulatan (persendirian), rumah nelayan, bangunan gudang dan perdagangan dan bangunan ibadah. Sedangkan kelompok bangunan yang dibangun setelah kemerdekaan namun tergolong kedalam benda cagar budaya juga masih bisa disaksikan. Untuk potensi budaya tak berwujud (intangible) juga terdapat beberapa kelompok seperti nilai sejarah kawasan, nilai seni dan budaya Melayu, dan permainan anak-anak dimana akan sangat mendukung kepada keberadaan bangunan Melayu apabila nilai budaya tak berwujud ini di lestarikan.

Seluruh potensi ini akan lebih bermanfaat apabila dilakukan pemeliharaan dan pelestarian sesuai dengan yang telah di atur didalam undang-undang cagar budaya agar tetap terjaga dan lestari sepanjang masa.
\end{abstract}

Kata Kunci : Potensi warisan budaya berwujud, warisan budaya tak berwujud, Wisata Sejarah dan Budaya. 


\section{ABSTRACT \\ STUDY POTENTIAL BANDAR SENAPELAN AS HISTORICAL AND CULTURAL TOURIST AREA IN PEKANBARU}

(Overview of the Architectural Heritage Assets Malay Traditional House)

Bandar Senapelan as the origin of the city of Pekanbaru has assets remains of architecture in the form of traditional Malay houses which have certain characteristics of a real historical evidence as to the development of the city of Pekanbaru. But because of there is no real comprehensive maintenance in this area until now, so it makes fear about the extinct of the historical evidence; if it so Pekenbaru will loose it's valuable identity of it's original town. Government rules in fact already exist but need to follow up by stakeholders of the city. Historical and cultural values found in Bandar Senapelan would be able to strenghten the identity of this area and it can also be an alternative for Community tourism area of the city.

This research aims to look at the extent to which potential owned by Bandar Senapelan which has assets of traditional Malay houses architectural relics, in order to be preserved and maintained so that it can be use into something more interesting, and to be an asset of the Malay history and culture tourism in the city of Pekanbaru. Mechanism of research will be done by the fishbone method. The position of this research is at the base of the research road map as mentioned in the research proposal.

The results obtained from the study that the potential intangible heritage (tangible) divided some groups. A group of traditional buildings such as the home circle (individual), the home of the fisherman, the warehouse building and the building trade and worship. While the Group of buildings that were constructed after the Indonesia independence day however belongs into the objects of cultural heritage can also still be seen. For intangible cultural potential (intangible) there are also some groups such as the history of the region, the value of art and culture, and children's games which will strongly support to the existence of a Malay building when this intangible cultural values are preserved.

The whole of this potential would be more beneficial if done in accordance with the maintenance and preservation that has been set up in the law of cultural heritage in order to stay awake and sustainable over time.

Key words: potential intangible cultural heritage, intangible heritage, History and culture.

\section{Pendahuluan}

Kota Pekanbaru sebagai Pusat Kebudayaan Melayu memelihara dan melestarikan warisan budaya Melayu ada. Jenis warisan budaya melayu berupa warisan yang tak berwujud/tak benda (Intangible Heritage) dan warisan budaya berwujud/benda (Tangible Heritage). Budaya yang berwujud dapat disebut Malay Intangible Heritage, yang masih ditemukan saat ini walaupun sudah mengalami perkembangan dari aslinya berupa Gurindam 12, baju melayu, masakan khas Melayu, adat istiadat. Sedangkan Tangible Heritage, seperti perkampungan Melayu, rumah-rumah tradisional Melayu, mesjid, surau dan lain- 
lain yang penuh dengan sejarah dan nilai-nilai kekerabatan ini sudah hampir musnah akibat dari modernisasi dan globalisasi. Tidak ada lagi orang Melayu yang tertarik untuk mempertahankannya dan melestarikannya karena dianggap tidak mempunyai nilai ekonomis lagi untuk saat ini.

Bandar Senapelan yang menjadi kawasan penelitian adalah negeri asal mula kota Pekanbaru yang mana masih memiliki aset peninggalan arsitektur rumahrumah tradisional Melayu dengan tipologi/bentuk arsitektur yang agak berbeda dengan daerah lain di Propinsi Riau, dan bentuk ini menjadi ciri khas dan sebagai bukti sejarah yang nyata. Menurut undang-undang RI no. 11 tahun 2010 tentang cagar budaya, rumah tradisional Melayu ini termasuk kedalam benda cagar budaya yang wajib untuk dilestarikan.

Namun karena tidak adanya pemeliharaan dan pemanfaatan yang terprogram dengan baik, maka dikhawatirkan keberadaannya akan punah dan masyarakat kota Pekanbaru tidak mempunyai bukti atau identitas lagi akan keberadaan kotanya, karena secara fisik kawasan ini adalah identitas Kota Pekanbaru .

\section{Tinjauan Pustaka}

\subsection{Arsitektur Tradisional Rumah Melayu aspek Tipologi dan Morfologi}

Dalam budaya Melayu, seni pembangunan rumah tradisional disebut dengan istilah "seni bina". Rumah memiliki arti yang sangat penting karena bukan saja sebagai tempat tinggal dimana kegiatan kehidupan dilakukan dengan sebaikbaiknya, tetapi juga menjadi lambang kesempurnaan hidup. Beberapa ungkapan tradisional Melayu menyebutkan rumah sebagai "cahaya hidup di bumi, tempat beradat berketurunan, tempat berlabuh kaum kerabat, tempat singgah dagang lalu hutang orangtua kepada anak"(Mahyudin Al Mudra, 2003).

Bentuk rumah tradisional Riau terdiri dari tiga bagian (Sudarmin 2014); bagian bawah berupa tiang-tiang konstruksi untuk rumah panggun,bagian tengah dalam bentuk ruang tiga dimensional tempat atau wadah kehidupan penghuninya dan bagian atas berupa atap yang bentuknya ada tiga macam seperti yang disebutkan diatas.

Keberadaan arsitektur rumah tradisional Melayu Riau selain menjadi identitas masyarakat Melayu juga berfungsi sebagai: untuk mengenal asal usul jati diri suatu bangsa, mengenal pemecahan masalah lingkungan yang telah dilakukan oleh para leluhur yang dijadikan sebuah pedoman atau arahan untuk generasi sekarang dan mendatang, menentukan perkembangan arah arsitektur dimasa datang, sebagai objek study dan penelitian, sebagai pertahanan budaya bangsa terhadap intervensi budaya asing didalam era globalisasi.

\subsubsection{Tipologi Rumah Melayu}

Bentuk bangunan rumah Melayu terdiri dari Rumah Bumbung Melayu, Rumah Belah Bubung dan Rumah Rabung”. Rumah Bumbung Melayu lebih banyak di sebut oleh para pendatang seperti orang Cina dan Belanda karena 
bentuknya berbeda dengan rumah mereka. Rumah Belah Bubung diberikan oleh orang Melayu karena bentuk atapnya yang terbelah oleh hubungan dua buah atap. Rumah Rabung atau Rubung (singkatan dari Perabung). Jenis rumah ini dipakai untuk membedakan rumah yang tidak memakai perabung seperti pondok di ladang dan gubuk yang sering disebut Pondok Pisang Sesikat.

\subsubsection{Morfologi Perkampungan Melayu}

Sejarah kehidupan orang Melayu dikenal dengan bahari, sehingga penyebaran perkampungan berada di sepanjang pinggiran air, baik pinggir lautan dan pinggiran sungai. Pola perkembangan perkampungan disepanjang pinggir air berbentuk linier atau bentuk pita. Hal ini disebabkan transportasi air merupakan yang utama didalam sistem ekonomi serta pendistribusian barang serta mengumpulkan produkproduk pertanian (Bambang Heryanto, 2011).Mendirikan bangunan di pinggiran Sungai Siak tidak dapat dipisahkan dari masyarakat, karena sungai merupakan jalur lalu lintas air dan mata pencaharian masyarakat sehingga proses perkembangan bentuk persil selalu mepertahankan terhadap pada tepian sungai. Menurut Paul Frank (dalam Hadi, 2002), bentuk morfologi didalam sebuah kota/ruang terbagi lagi menjadi; a) Bentuk Ruang (spatial form), b).Bentuk Lahiriah (corporeal form), c).Bentuk Visual (visual form, d). Bentuk Intensi ber-Guna (Purposive Intention).

\subsection{Sejarah Bandar Senapelan}

Asal mula nama Pekanbaru (Pekan yang baharoe) dahulunya dikenal dengan nama "Bandar Senapelan" dipimpin oleh seorang Kepala Suku yang disebut Batin. Daerah ini terus berkembang menjadi kawasan pemukiman baru dan seiring waktu berubah menjadi Dusun Payung Sekaki terletak di muara Sungai Siak yang kemudian dikenal dengan Bandar Bandar Senapelan. Hal ini terbukti dengan ditempatkannya seorang datuk syahbandar dari kerajaan Johor di Bandar Senapelan tahun 1511 menggantikan kedudukan Raja Muda yang dihapuskan. Bandar ini terus berkembang dan Sungai Siak yang berada di sepanjang Bandar ini telah menjadi Pusat Kegiatan Ekonomi yang cukup besar ${ }^{1}$.

Dengan hadirnya pasar perkembangan permukiman Bandar Senapelan semakin pesat terutama di muara-muara sungai kecil seperti Muara sungai Sago, sungai Limau, sungai Sail, sungai Tenayan dan sungai air hitam di Kampung Dalam, Kampung Baru, Tanjung Rhu, Tampan, Palas dan Tenayan ${ }^{2}$.

\subsection{Teori Pelestarian Warisan Sejarah Budaya}

Pelestarian sumberdaya budaya perlu didasari oleh pertimbangan seperti beberapa hal seperti nilai penting yang cukup luas dalam aspek budaya (cultural materials) yaitu 4 aspek nilai penting yang dapat dijadikan dasar pertimbangan penetapan perlunya pelestarian, yaitu aspek keilmuan,aspek kesejarahan, aspek kebudayaan, dan aspek kemasyarakatan (Schiffer dan Gummerman, 1979). Penetapan kawasan dan pelestarian bangunan diambil dan/atau digariskan

\footnotetext{
${ }^{1}$ www.pekanbaru.go.id

${ }^{2}$ Majalah Kubah Senapelan, 2007
} 
berdasarkan penilaian atas : tingkat permasalahan yang dihadapi, potensi, serta prospek yang dimiliki kawasan kota tersebut.

\subsection{Teori Kepariwisataan Warisan Sejarah dan Budaya}

Undang - Undang No. 25 Tahun 2000 tentang Program Pembangunan Nasional, mengamanatkan bahwa tujuan pembangunan pariwisata adalah; i). mengembangkan dan memperluas diversifikasi produk dan kualitas pariwisata nasional; ii). berbasis pada pemberdayaan masyarakat, kesenian dan sumber daya (pesona) alam lokal dengan memperhatikan kelestarian seni dan budaya tradisional serta kelestarian lingkungan hidup setempat dan; iii) mengembangkan serta memperluas pasar pariwisata terutama pasar luar negeri.

Pariwisata sejarah adalah sebuah kegiatan kepariwisataan yang menampilkan nilai-nilai sejarah dari suatu bangsa, agama, etnis dan lain sebagainya yang mana salah satu tujuan utamanya adalah meningkatkan rasa nasionalisme dan memperjelas identitas suatu bangsa. Sejarah juga sebagai mata rantai suatu peristiwa yang mempunyai rangkaian cerita terhadap sebuah perjuangan untuk meraih sesuatu.

\section{Metode}

Penelitian dilakukan di Kelurahan Bandar Senapelan Kota Pekanbaru pada bangunan tua dan rumah tradisional serta potensi lainnya.Berdasarkan tinjauan ke Bandar Senapelan untuk memperoleh potensi sebagai kawasan wisata sejarah dan budaya di Pekanbaru, penelitian ini dipilih pendekatan fenomenologik dengan metode deskriptif. Sehingga dengan metode ini bentuk arsitektur dan potensi lainya dapat diuraikan. Pengumpulan data dilakukan dengan survey ke lapangan untuk memperoleh data fisik dengan melakukan teknik pemotretan, pencatatan dan pengamatan untuk mendapatkan data fisik bagunan dan kawasan.Adapun bentuk kegiatan yang akan dilakukan meliputi :

a. Survey data primer berupa tinjauan langsung ke lokasi kawasan mendapatkanpotensi Bandar Senapelan sebagai sebuah aset sejarah dan budaya Melayu untuk dilestarikan keberadaannya sehingga menjadi kawasan wisata sejarah dan budaya di Pekanbaru

b. Survey data sekunder mencari informasi dari berbagai pihak.

c. Studi literatur yang berhubungan dengan nilai-nilai budaya arsitektur tradisional dan Kepariwisataan Warisan Sejarah dan Budaya

d. Penganalisaan tentang potensi budaya melayu yang berwujud/ benda (Malay Tangible Heritage) dan tak berwujud (Malay Intangible Heritage)

e. Survey data primer berupa tinjauan langsung ke lokasi kawasan mendapatkanpotensi Bandar Senapelan sebagai sebuah aset sejarah dan budaya Melayu untuk dilestarikan keberadaannya sehingga menjadi kawasan wisata sejarah dan budaya di Pekanbaru

f. Survey data sekunder mencari informasi dari berbagai pihak. 
g. Studi literatur yang berhubungan dengan nilai-nilai budaya arsitektur tradisional dan Kepariwisataan Warisan Sejarah dan Budaya

h. Penganalisaan tentang potensi budaya melayu yang berwujud/ benda (Malay Tangible Heritage) dan tak berwujud (Malay Intangible Heritage)

i. Menyimpulkan hasil penelitian

\section{Hasil}

Potensi Budaya Berwujud berupa tipologi rumah Melayu berupa:

1. Bangunan perumahan masyarakat, rata-rata bangunan perumahan masyarakat pada kawasan ini yang masih tersisa dibangun semenjak akhir abad 18 dan awal abad 19, dengan demikian bangunan ini telah masuk kepada bangunan cagar budaya menurut Undang-undang tentang cagar budaya no 11 tahun 2010 .

2. Dilihat dari tipologi bahwa bangunan asli rumah Melayu dengan rumah yang terdapat di kawan ini sudah mulai banyak adanya percampuran unsur-unsur arsitekturnya, salah satunya dari susunan bentuk ruang dalam yang sudah banyak mengalami perubahan akibat dari kebutuhan pemilik sehingga bentuk atap juga mengalami perubahan. Kebanyakan rumah Melayu di kawasan ini mempunyai atap limas (bentuk ini dipengaruhi oleh Belanda).

3. Bangunan perdagangan juga masih terjaga tipologinya, baik dari bentuk arsitektur maupun jenis material bangunannya, hanya saja sudah banyak yang sengaja di rubuhkan dan diganti dengan bangunan baru. Namun yang tersisa sudah cukup memberikan inspirasi kepada sebuah kota mengenai kejayaan masyarakat Bandar Senapelan pada zamannya.

4. Bangunan Ibadah, yang sangat menyedihkan sudah tidak ada lagi yang tersisa, padahal bangunan yang paling awal dibangun oleh Sultan pada waktu itu adalah Mesjid yang sangat sarat dengan sejarah. Akan tetapi tidak ada lagi yang tersisa.

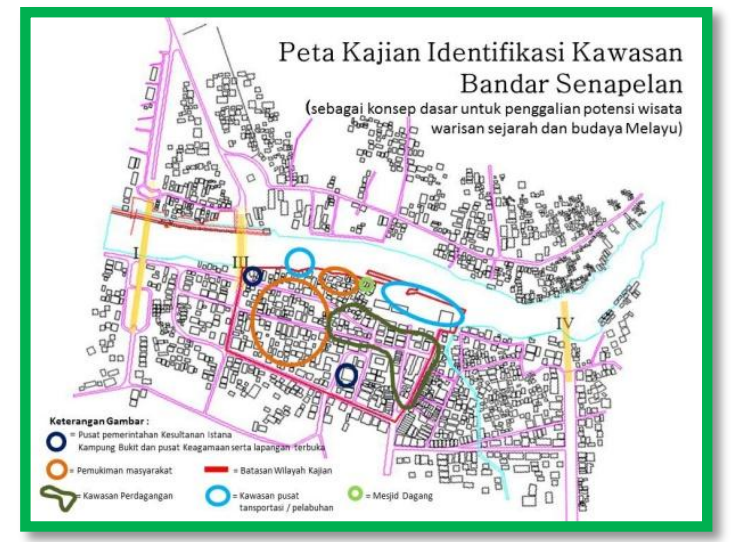

Gambar. Peta Kajian pada Kawasan Bandar Senapelan 


\section{Pembahasan}

\subsection{Identifikasi Potensi budaya tangible dan budaya intangible Di Bandar Senapelan}

Perkembangan Bandar Senapelan pada saat ini tidak bisa melepaskan diri dari tekanan perkotaan perlu mendapat perhatian dan segera dilakukan penilaian terhadap keberadaan kawasan ini. Pada tahap awal identifikasi yang dilakukan adalah terhadap potensi budaya tangible (berwujud) yang terlihat. Penilaian bangunan terhadap ktriteria konservasi atau pelestarian adalah sebagai berikut;

1. Estetika Bangunan

Estetika bagunan yang memiliki nilai keindahan arsitektur, pada fasade bangunan dimana bentuk terlihat sesuai dengan fungsi bangunan, struktur bangunan memiliki nilai estetis dan ornament pada bangunan baik pada dinding, jendela, pintu dan atap memiliki gaya arsitektur yang khusus.

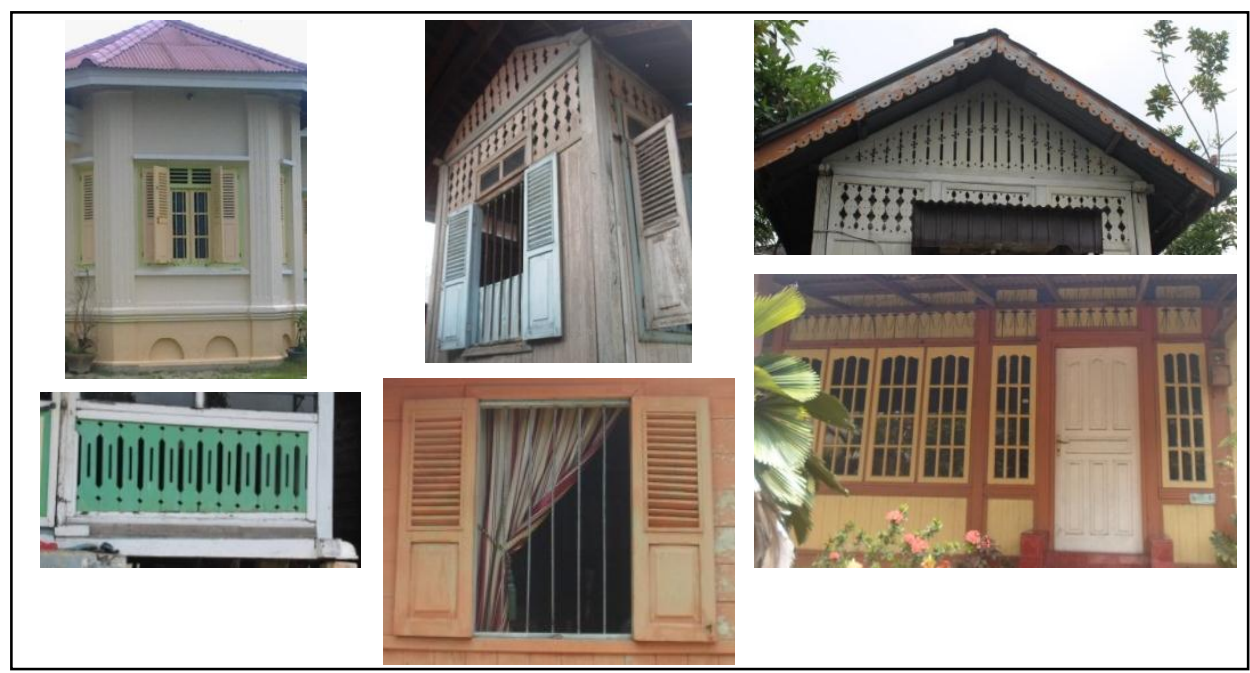

Gambar. Bagian estetika pada bangunan tradisional Melayu

2. Kejamakan

Bentuk dan jumlah bangunan atau rumah tradisional yang ada di Bandar Senapelan memiliki gaya berbeda sesuai dengan tahun bangunan. Namun gaya yang berbeda ini masih didalam satu garis arsitektur Melayu walaupun sudah terdapat percampuran gaya.

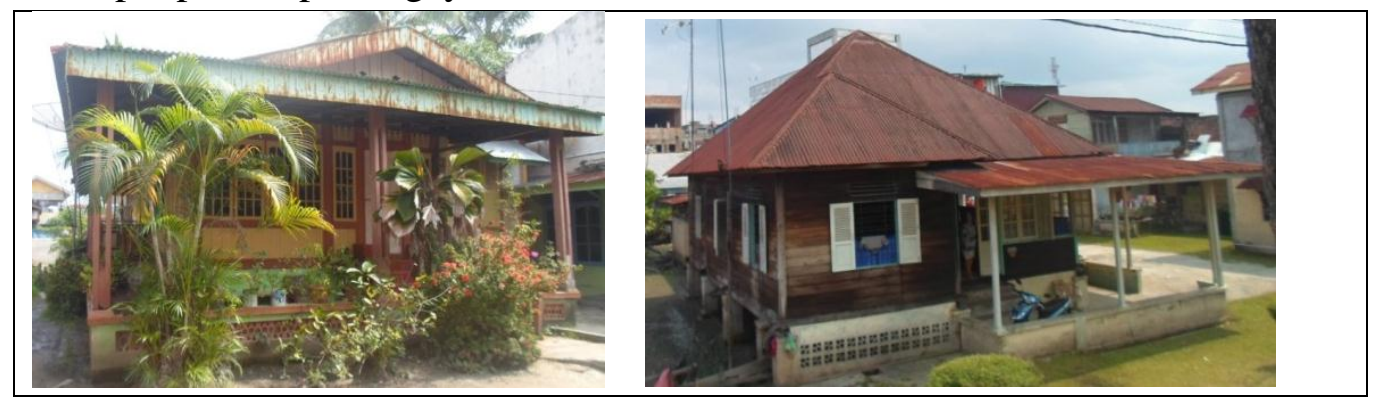




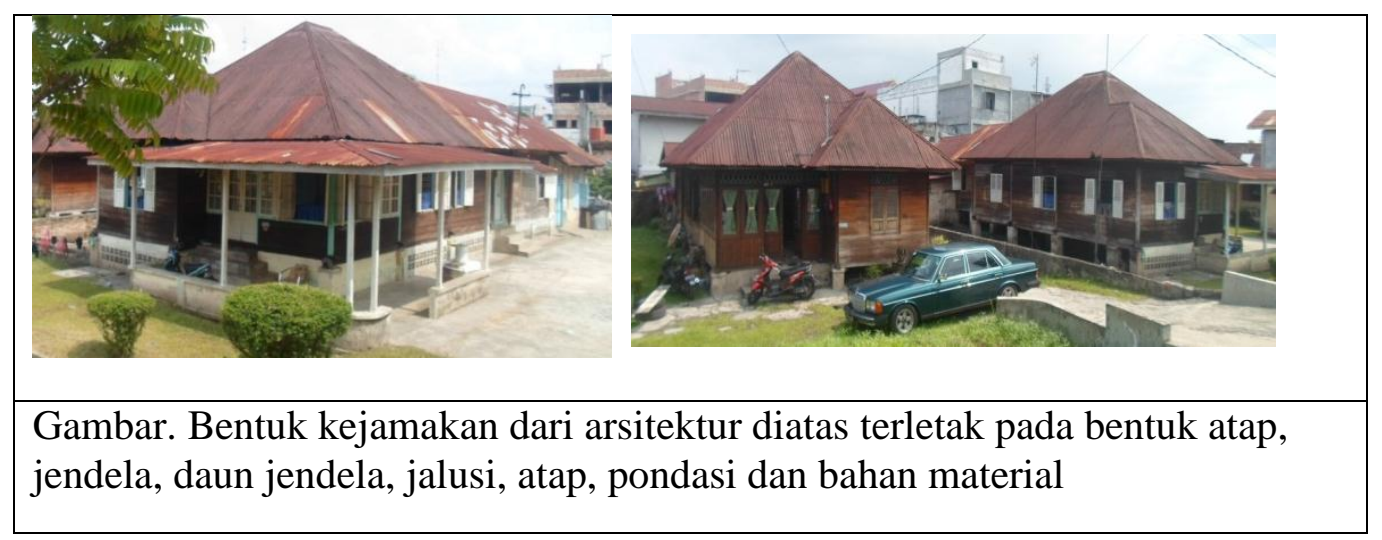

3. Kelangkaan

Bangunan yang ada di kawasan Badar Senapelan memiliki nilai-nilai historis kawasan, kawasan yang menjadi asal mula dari kota Pekanbaru ini tidak boleh di sia-siakan dan dilupakan keberadaannya.

4. Keistimewaan

Bangunan untuk rumah tinggal material yang digunakan lebih bayak menggunakan material dari kayu sehingga bangunan yang sudah berumur lebih dari seratus tahun tidak terjadi kerusakan yang cukup berarti walaupun tidak dilakukan perawatan bangunan.

5. Memperkuat Kawasan

Bangunan-bangunan tersebut sesuai dengan perkembangannya akan memperkuat kawasan sebagai kawasan yang memiliki nilai sejarah awal perkembangan kota Pekanbaru sehingga menjadi identitas kota

Potensi budaya intangible atau tidak berwujud berupa tari-tarian, nyanyian, music tradisional, dendang syair melayu, Kompang talempong, tenunan kain, upacara tradisional pernikahan, makanan tradisional dan permainan anak.

\subsection{Identifikasi Potensi Pariwisata Sejarah Dan Budaya Di Bandar Senapelan}

Identifikasi potensi pariwisata sejarah dan budaya di Bandar Senapelan terdapat beberapa aspek nilai penting yang dapat dijadikan dasar pertimbangan penetapan perlunya pelestarian:

1. Aspek Keilmuan

Kawasan ini bisa dijadikan laboratorium penelitian arsitektur, penelitian perkotaan, penelitian sosial budaya masyarakat melayu, penelitian bahari dan lain sebagainya .

2. Aspek Kesejarahan

Kawasan tersebut menjadi bukti sejarah mula perkembangan kota Pekanbaru khususnya tentang sejarah kesultanan Riau. Sejarah Bandar Senapelan juga merupakan jati diri dari warga kota Pekanbaru yang sarat dengan budaya melayu yang notabene telah berurat dan berakar. 
3. Aspek Kebudayaan

Dengan melestarikan kawasan tersebut sehingga budaya melayu akan terjaga dan terlihat dalam kehidupan bermasyarakat sehari-hari.

4. Aspek Kemasyarakatan

Kawasan yang memiliki karakter budaya yang kuat sehingga akan membentuk hubungan kekerabatan masyarakat akan kuat dengan penerapan akan nampak pada tatanan sosial.

Dalam menggali potensi kepariwisataan sejarah dan budaya ini, terdapat juga beberapa hal yang harus dianalisa dari segi peruntukkan kawasan kota melayu seperti;

1. Pusat pemerintahan, pusat pemerintahan pada kawasan ini diidentifikasi letaknya di sekitar mesjid raya (saat ini) dan juga di tepi sungai siak bagian barat yaitu rumah singgah sultan Siak

2. Pusat keagamanaan, pada saat ini masih pada posisi yang sama yaitu mesjid raya, dan sekitar pemakaman marhum pekan. Walaupun mesjid lama sudah tidak ada lagi, akan tetapi komplek makam bisa dijadikan bukti keberadaan mesjid tua tersebut.

3. Lapangan terbuka, yang menjadi salah satu ciri perkotaan melayu tidak teridentifikasi di kawasan ini.

4. Pusat transportasi, terdapat dua jenis pelabuhan di sepanjang bandar senapelan, namun hanya satu pelabuhan yang masih dipergunakan oleh masyarakat

5. Kawasan perdagangan, kawasan ini sangat kental terlihat dan sangat membutuhkan penanganan yang segera. Penggunaan rumah lama dan bangunan lama untuk toko, gudang dan aktifitas perdagangan yang skala besar dan berat akan cepat merusak struktur dan konstruksi bangunan tersebut.

6. Permukiman, kawasan pemukiman di daerah ini masih terlihat walaupun sudah hampir habis.

\section{Kesimpulan}

Dari hasil kajian potensi aset arsitektur Melayu di Bandar Senapelan ini di ambil beberapa kesimpulan berkaitan dengan beberapa hal seperti:

Berkaitan dengan bentukan fisik yaitu Arsitektur Tradisional Melayu perlu di lakukan inventarisasi secara menyeluruh dengan pendokumentasian dan penggambaran ulang ke seluruhan bangunan termasuk ornamen, membuat data kepemilikan yang benar yang berada pada lokasi penelitian.

Berkaitan dengan penetapan fungsi ruang, perlu dilakukan penataan yang lebih baik oleh Pemerintah Kota guna menjaga agar kawasan ini tidak mengalami degradasi yang sangat tajam yang akan mengancam keberadaan kawasan secara menyeluruh. Adanya intervensi dari pembangunan modern yang akan mengancam 
keberadaan bangunan tradisional ini perlu di sikapi yang sangat serius apabila kawasan ini akan di jadikan pusat kebudayaan Melayu di Kota Pekanbaru.

Berkaitan dengan fungsi kepariwisataan yang akan di tetapkan oleh Pemerintah, perlunya melakukan identikasi aktifitas kepariwisataan yang sesuai dengan rumah dan bangunan yang ada disebut juga dengan adaptive-reuse, apabila tidak dilakukan maka penggunaan bangunan dan rumah tradisional tidak tepat akan merusak bangunan.

\section{Saran}

Perlunya sinergi segala pihak dengan tanpa mengedepankan keinginan individu dan kelompok dirasa perlu diciptakan. Seperti kelompok masyarakat sadar budaya dan wisata Bandar Senapelan, yang mana tugas utamanya adalah sebagai penyaring dan mengusulkan program-program bidang kemasyarakatan dan pelestarian pada kawasan mereka agar bisa sejalan dengan cita-cita Pemerintah Kota.

\section{Daftar Pustaka.}

Boniface, Procilla and Fowler, Peter.J.,1993, Heritage and Tourism in the Global Village, Routledge, London

Boniface, Pricilla, 1995, Managing Quality Cultural Tourism, Routledge, London and New York

Butler, R. and Waldbrook, L., A New Planning Tool: The Tourism Opportunity Spectrum. Journal of Tourism Studies, 1. Pp.25-36. ISBN 1476-6825

Gunn, Clare, A., 1994, Tourism Planning, 2nd Ed., Taylor and Francis, USA.

Hamidy, UU,2009, Jagad Melayu Dalam intasan Budaya di Riau, Bilik Kreatif Press.

Mudra, Mahyudin Al, 2003, Rumah Melayu, Adicita.

Marni, Tien, 2009, Yang Berfaedah Dalam Kisah, Dinas Kebudayaan dan Pariwisata Provinsi RIAU

Rahman, Elmustian. Marni, Tien dan Zularnain, 2003, Unri Press

Soetomo, Sugiono, 2009, Urbanisasi \& Morfologi. Graha Ilmu

Sudarmin, Yoserizal, 2007, Kajian Morfologi Rumah Tradisional Rumah Lontik Kampar, Jurusan Arsitektur Fakultas Teknik, Universitas Lancang Kuning.

Samra, Boby, 2011, Perubahan Ruang Dalam Rumah Lama di Kawasan Senapelan Pekanbaru, Universitas Bung Hatta.

Wahid, Julaihi, 2013, Teori Arsitektur, Graha Ilmu.

Wahyuningsih,BA dan Rivai Abu, 1984 Arsitektur Tradisional Daerah Riau, Dpartemen Pendidikan dan Kebudayaan, Proyek Inventarisasi dan Dokumentasi Kebudayaan Daerah

Wanghalib, 1980, Sejarah Pekanbaru, Pemerintah Pekanbaru. 
